\title{
POSTOPERATIVE BILATERAL UPPER LIMB GANGRENE IN NEONATE
}

\author{
Anand Srivastava ${ }^{1}$, Priyadarshini M. Bentur², Manjunath Jajoor ${ }^{3}$
}

\section{HOW TO CITE THIS ARTICLE:}

Anand Srivastava, Priyadarshini M. Bentur, Manjunath Jajoor. "Post-operative Bilateral Upper Limb Gangrene in Neonate". Journal of Evolution of Medical and Dental Sciences 2014; Vol. 3, Issue 53, October 16;

Page: 12378-12381, DOI: $10.14260 /$ jemds/2014/3637

\begin{abstract}
We are reporting a very unusual case of Bilateral upper limb gangrene in postoperative period in 3 day old neonate, who was admitted for the correction of congenital intestinal fistula with meckel's diverticulum in exomphalos minor. A negative sepsis screen, absence of evidence of hypercoagulable state prompted us to make the diagnosis of IDIOPATHIC BILATERAL UPPER LIMBGANGRENE in this newborn. Because of the rarity we are reporting this case with wide review of literature.
\end{abstract}

KEYWORDS: Neonatal Gangrene.

INTRODUCTION: Peripheral limb ischemia and gangrene is uncommon in neonatal period. This condition may be precipitated by a wide variety of factors, prenatal and perinatal, leading to vascular occlusion. ${ }^{1}$ Treatment of this condition is supportive with prevention of sepsis. Once gangrene was established surgical debridement and amputation of toes was done.

CASE REPORT: A 3 day old neonate, weighing $1.5 \mathrm{~kg}$ was admitted due to Congenital intestinal fistula with meckel's diverticulum in exomphalos minor and posted for corrective surgery. On preoperative evaluation, it was a full term normal delivery with no complications during prenatal and perinatal period.

There were no predisposing factors like arterial thrombosis, emboli, trauma, congenital heart disease, sepsis, coagulopathy, polycythemia, umbilical catheterization and birth trauma. Following investigations were done during preoperative evaluation-Hemoglobin- $20.8 \mathrm{~g} / \mathrm{dl}$, Hematocrit- $60.4 \%$, Platelet count- $313^{\wedge} 10^{3}$ lakh/microlt., T.L.C-12.97 $\wedge 10^{3} /$ microlitre, D.L.C- Neutrophils $-59 \%$, Lymphocytes-36\%, Monocytes-05\%, Eosinophil -00\%, Basophil -02\%, R.B.S- 122 mg\%, Blood urea35.0, Serum creatinine-0.9, Total Bilirubin-14.8 mg/dl, Serum Sodium-135.2mmol/l, Serum Potassium-5.45 mmol/l, Bleeding time- $2.10 \mathrm{~min}$, Clotting time-5.15 min, Ultrasound abdomenBilateral cryptorchidism, Blood culture-No growth of microorganism, Chest X-Ray - Normal, Protein C \& S was not done due to unaffordability and no evidence of coagulation abnormality.

On the morning of surgery baby developed peripheral cyanosis because of which surgery was postponed and ECHO was done ECHO-Normal heart, Normal LVEF, No clot/ vegetation's.

Next day baby was taken up for surgery under general anaesthesia, during intraoperative period to rule out congenital anorectal abnormalities surgeons administered saline through the anus leading to development of hypothermia and bradycardia which was treated with Atropine and warming the baby with warmer. After 30-45 minutes of warming the baby, bilateral skin changes were noticed in the upper limb fingers, which was followed by peeling of skin on POSTOP DAY 1 and established dry gangrene BY POSTOP DAY 3. These BILATERAL changes were attributed as warmer induced injury by the surgeons. 


\section{CASE REPORT}

During the post- operative stay child was hemodynamically stable with no evidence of infection. After three weeks of hospital stay child was discharged and sent home.

Intravenous antibiotics amikacin and ceftriaxone was given during hospital stay and dressing of the involved areas with silver sulfadiazine ointment was carried out twice daily.

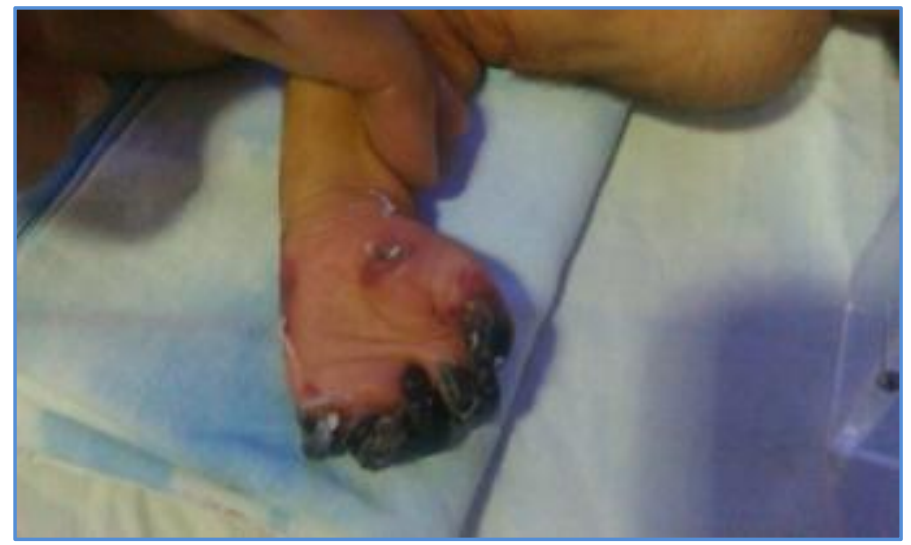

\section{FIG. 1: SHOWS GANGRENE OF FINGERS OF LEFT HAND}

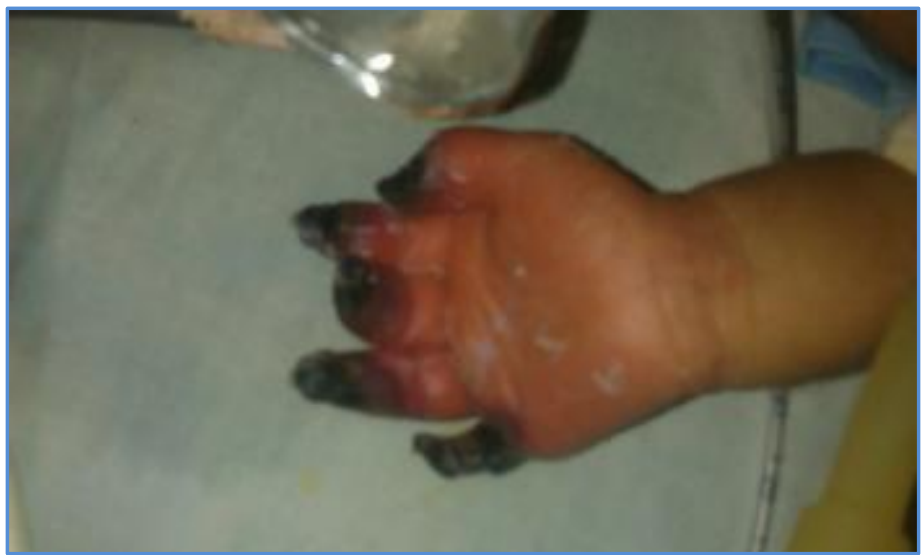

\section{FIG. 2: SHOWS GANGRENE OF FINGER OF RIGHT HAND}

DISCUSSION: Bilateral upper limb gangrene in neonates is rare event. Etiology is not identified in most cases and management is usually conservative ${ }^{2}$ with debridement and amputation of gangrenous part. It results from diminished perfusion of a part of the body, usually the extremities. Known etiologies include hypercoagulable state, in uteroarterial thrombosis, polycythemia, maternal diabetes, birth trauma, prematurity, ${ }^{2}$ congenital syphilis, ${ }^{3}$ umbilical artery cannulation, ${ }^{4}$ intravenous hyperosmolar infusions and sepsis ${ }^{5}$, In majority of cases, an etiological factor is not identified. Upper limb gangrene is more frequent compared with that of lower limbs. ${ }^{2,4,5}$

In our case, sepsis and other causes were ruled out based on investigations. Also as parents were worried, this ruled out physical abuse. Blister formation (indicating superficial skin damage) and gangrene have been described with frostbite in adults. ${ }^{6}$ 
Management includes systemic antibiotics and dressing with local antibiotics so that first infection gets controlled before debridement of gangrenous part.

Early surgical intervention is indicated in the presence of severe or progressive ischemic changes. More often, there has been progression to spontaneous slough or autoamputation 5,7 or surgery and limited amputation. In our index case blisters were present in upper limb and no effect on the lower limb. Infant recovered with debridement and conservative amputation. Kothari et al ${ }^{8}$ managed four cases of lower limb gangrene in neonates, all presented with bilateral gangrene and required amputation and in two of them no cause was found.

Also Nagai et $\mathrm{al}^{9}$ described the two cases of intrauterine gangrene of bilateral lower limb complicated by twin-to-twin transfusion syndrome requiring below knee amputation. In our index case, presentation was bilateral (warmer induced injury should be unilateral), almost symmetrical, with clear line of demarcation as in dry gangrene and amputations of digits was required. Sepsis can lead to gangrene but as sepsis has been ruled out in the index case and no other etiology found, therefore it has prompted us to make the diagnosis of idiopathic bilateral upper limb gangrene in this newborn.

\section{REFERENCES:}

1. Alapati Srihari et al. A Rare case report of gangrene in newborn. J Clin Biomed Sci 2012; 2 (1).

2. Krisnamurthy S, Singh V, Gupta P. Neonatal frostbite with gangrene of toes. Pediatr Dermatol. 2009; 26: 625-6. [PubMed: 19840331].

3. Musa AA. A review of diagnosis and modes of presentation and modes of presentation of tropical idiopathic lower limb gangrene. Afr Health Sci. 2005; 6: 49-50. [PMCID: PMC1831962] [PubMed: 16615828].

4. Giannakopoulou C, Korakaki E, Hatzidaki E, Manoura A, Aligizakis A, Velivasakis E. Peroneal nerve palsy: A complication of umbilical artery catheterization in the full-term newborn of a mother with diabetes. Pediatr. 2002; 109: e66.

5. Ibrahim H, Krouskop R, Jeroudi M, McCulloch C, Parupia H, Dhanireddy R. Venous gangrene of lower extremities and Staphylococcus aureus sepsis. J Perinatol. 2001; 21:136-40. [PubMed: 11324361].

6. Kanzenbach TL, Dexter WW. Cold injuries. Protecting your patients from the dangers of hypothermia and frostbite. Post Grad Med. 1999; 105: 72-8.

7. Letts M, Blastorah B, al-Azzam S. Neonatal gangrene of the extremities. J Pediatr Orthop. 1997; 17: 397-401. [PubMed: 9150032]

8. Kothari PR, Gupta A, Kulkarni B. Neonatal lower extremity gangrene. Indian Pediatr. 2005; 42: 1156-8. [PubMed: 16340058].

9. Nagai MK, Littleton AG, Gabos PG. Intrauterine Gangrene of the lower extremity in the newborn: A report of the two cases. J Pediatr Orthop. 2007; 27: 499-503. [PubMed: 17585256]. 


\section{CASE REPORT}

\section{AUTHORS:}

1. Anand Srivastava

2. Priyadarshini M. Bentur

3. Manjunath Jajoor

\section{PARTICULARS OF CONTRIBUTORS:}

1. Post Graduate, Department of Anaesthesia, J.J.M. Medical College.

2. Associate Professor, Department of Anaesthesia, J.J.M Medical College.

3. Professor, Department of Anaesthesia, J.J.M. Medical College.

\section{NAME ADDRESS EMAIL ID OF THE} CORRESPONDING AUTHOR:

Dr. Priyadarshini M. Bentur,

W/o Dr. A. R. Veeresh,

\# 716, $9^{\text {th }}$ Main,

P.J. Extension, Davanagere-577002,

Karnataka.

Email: priyadarshiniveeresh@gmail.com

Date of Submission: 23/09/2014.

Date of Peer Review: 24/09/2014.

Date of Acceptance: 06/10/2014.

Date of Publishing: 16/10/2014. 